\title{
On the Promises of Hope in Perilous Times
}

\author{
Winston C. Thompson \\ The Obio State University
}

Against a backdrop of increasingly contentious political times, it would seem that many citizens across the globe recognize themselves as constrained by entrenched and compounded systems of social and institutional injustices; for many attentive to these trends, it might be difficult not to reach the conclusion that the very fate of democracy may well hang in the balance. ${ }^{1}$ Given this general state of affairs, even those citizens drawn to the hard work of social and political improvement may slide into a sense of fatalism or despair in encountering a system that, from their view, repeatedly rewards those who appear as bad-faith actors, frustrating purportedly cooperative endeavors for communal benefit.

It is in this context that Sarah Stitzlein's Learning How to Hope: Reviving Democracy Through our Schools and Civil Society offers meaningful salve to the pains of the contemporary moment in the United States of America. Through the book, Stitzlein sews together an awareness of many of these complicated dimensions of civic life and invites the reader to further consider how education might be tasked with more than only "knowledge work" in the preparation for participation in the same. That is, how might education ready citizens, beyond supplying them with the mere factual knowledge of the systems within which they operate, so that they might develop something of the various clusters of dispositions and/or outlooks required to persevere in the often-difficult labor of democracy? By this book's analysis, an especially promising answer is found in hope.

Stitzlein's text affirms a pragmatist form of hope that is greater than simple "wishes, optimism, or ... grit." Embedded within a meliorism committed to human action's potential to improve our circumstances, she offers a view of hope that is characterized as a substantive engagement with our common future as citizens and, as such, is viewed in this text as essential to the very practice of democracy. ${ }^{2}$ Within these pages, Stitzlein builds upon this perspective on hope 
to offer not only an account of "what hope is, why it matters to democracy, and how to teach it," but to also use this conceptualization of hope as an entry into a quite thoughtful meditation on the unique features of civic/political life in contemporary "hyper-partisan" western democracies. ${ }^{3}$

As a citizen who cannot help but share Stitzlein's observation of the troubling times within which we live, I find myself deeply appreciative of the carefulness and nuance of her work in this timely text- indeed, I ought to note that I am particularly appreciative of the fine accomplishments expressed in her sixth chapter, "Learning How to Hope." For other readers who are, similarly, enthusiastic supporters of engaged civic activities, this book represents a nuanced appreciation of the role of education in civic life. This is a real boon, as, to my mind, few topics could be as important as preparation for the weighty work of living well amongst and with others-especially as those others are so very often dissimilar to ourselves in ways that seem to perplex not only our person, but our very sense of possibility within this ongoing relationship. In this delicate and indispensable work, hope might, indeed, be one promising resource amongst many.

Still, after reading this fine contribution, I remain less enamored of hope than I expect Stitzlein might have desired. This hesitation regarding hope is not quite a disagreement with the book's premise; indeed, in her first chapter, "Hope in America?" Stitzlein encourages her reader to join her in the task of "exploring" hope. Taking that invitation seriously, I would like to continue to prod some of the foundational views likely undergirding the project. Rather than attending to specific passages or providing a nuanced reading of particular elements of Stitzlein's valuable arguments (I trust that this is ably provided by the diligent authors of the other reviews appearing alongside my own), in the pages to follow I aim to pose a few questions (i.e., Is hope compelling? When ought we not teach hope?) of the book's central subjects, namely, the necessity of hope and the appeal of educating for it, with the intent of opening further discussion about the terrific themes and quite provocative analysis provided by Stitzlein. 


\section{QUESTION 1: IS HOPE COMPELLING?}

On my understanding, the core project of the book is to "argue that schools and civil society should nurture hope as a set of habits that disposes citizens toward possibility and motivates citizens to act to improve their lives and, often, those of others." ${ }^{.4}$ I suspect that some readers may hesitate in encountering this proposal. In truth, much of my own thinking about this project emanates from my own hesitation.

Towards identifying a root cause for hesitation related to this central aim, I below sketch some possible reasons that one might not view Stitzlein's pragmatist form of hope as desirable, necessary, and/or sufficiently accessible for the civic tasks ahead.

\section{REASON A: HOPE DISTRACTS FROM POLITICAL REALITY}

In suggesting that hope distracts from political reality, one might wonder about the ways in which political campaigns trade on a sense of the possible in a manner that prevents a sober look at the realities of a situation. Though Stitzlein identifies hope as a keen motivator, I would call complementary attention to the rhetorical role of hope as a motivational distraction. That is to ask, how might a view of the possible contribute to obscuring an accurate assessment of our lived circumstances? Perhaps, in many cases, might it be objectively "better" to encourage an engaged disposition to solving the real and grounded social issues of our time rather than fixing our gaze on the ideals of a further horizon? Pragmatist hope (well described by Stitzlein with subtlety and care) might seem rather immaterial to this form of meliorism (though it might align with the views expressed by writer Ta-Nehesi Coates, as quoted in Stitzlein's powerful third chapter, "Hope as Habits"). To be clear, this commitment to solving the problems before us is certainly melioristic as it endorses human capacities for improving our world, but it seemingly need not engage a sense of hope in order to accomplish this. Though hope might be held alongside this dedication to the work of addressing a flawed world, its status may be incidental rather than essential to that civic project. While political campaigns might have an interest in leveraging a voting population's sense of hope's desirability, perhaps very 
much of democracy's labor is possible without it. Posed differently, one might wonder whether Stitzlein would entertain the possibility that citizens might participate within an effective democracy without it being a hopeful democracy (I will further explore this below). To my mind, it seems that hope could (in some moments) motivate inaction just as easily as it might prompt interventions, such that I find myself wondering whether Stitzlein's project is truly as focused as she perceives on hope itself or some potential by-product-of-hope (about which I, and others, might be more enthusiastic) instead.

\section{REASON B: HOPE IS NOT ESSENTIAL FOR CIVIC ENGAGEMENT}

In expanding upon ideas from the previous reason, it is not difficult to wonder if hope is as civically necessary as Stitzlein claims. Must citizens consider the prospective possibility of improved circumstances if they seek motivation for civic engagement? One might ask, what becomes possible for a democracy that aspires to educate citizens to remain steadfast in their political commitments in spite of their hope-agnosticism? Or, stronger still, what might be wrought by those who persevere despite a sense of true hopelessness? Of course, to be clear here, I do not mean to imply that one being uncertain about or hesitant in relation to hope necessarily entails a slide into "hopelessness" (to be fair, this is a term which almost exclusively appears only in the first chapter of Stitzlein' book). Instead, I submit that analyses at the intersection of hope, education, and democracy might achieve a broader-than-previously-envisioned catalogue of civic actors by use of "non-hopeful" as an adjectival term associated with the type of citizens I am here calling my readers to consider.

In giving further form and substance to this category of citizen, again I ask, might it be possible to motivate engagement with the difficult work of democracy for reasons that are wholly independent of hope's future oriented dimensions? Here, I envision expressive (or, perhaps, categorically emotive) forms of political participation. Imagine the citizen who, in describing their

civic motivation, might accurately state: "I am not now acting because I expect change for the better, but I am acting because such action is the appropriate 
response to this particular moment or pattern of injustice. My political action is symbolic and/or represents a communication that could not be otherwise achieved but by this form of engagement." Even without the content of such expressive/emotive communication disclosed in the example above, the possibility of such a category of citizen seems plausible.

\section{REASON C: HOPE IS A LUXURY FOR SOME}

Finally, how might the idea that hope is something of a luxury for some persons impact arguments that locate it as essential for democratic participation? In the later portion of "Hope as Habits" (entitled, Shortcomings of Pragmatist Hope), Stitzlein engages aspects of this vexing (for her unfolding argument) worry. ${ }^{5}$ She, to my mind accurately and with appropriate subtlety, depicts the circumstances under which some citizens might not regard hope as an extant option for them. Long-term and pervasive patterns of disadvantage and despair might visit upon persons within some communities (here Stitzlein largely flags communities that rest at the intersection of racial and economic marginalization) a quite reasonable sense that hope is a too-distant-to-be-applicable response or is, otherwise, simply the wrong response to their lived experiences. While she engages a robust coterie of thinkers across various traditions in defense and criticism of the pragmatist form of hope she defends, I wonder whether her tactic - to acknowledge the shortcomings of hope as a desideratum for some persons under some circumstances, while nonetheless continuing to support the idea that hope functions as a necessary element of the collective civic project — satisfies. In raising this reason, I mean to ask what might we regard as the practical implications of the acknowledgement that hope might not be universally accessible and appropriate? How ought we engage the preparation for challenging civic work, as this represents the educational core of Stitzlein's project, when practiced amongst those for whom pragmatist hope is, perhaps, a too "indulgent" aim? Despite hope's rhetorical popularity within these populations, what manner of educational work serves the interests and the circumstances of the racially and economically marginalized? 


\section{QUESTION 2: WHEN OUGHT WE NOT TEACH HOPE?}

Given description of these issues of access to, and the appropriateness of, hope, I find myself wondering when ought one avoid teaching hope? That is, as it strikes me that hope might not be desirable or accessible, under all contexts, how might one come to recognize sufficiently good conditions under which to teach something other than hope to the categories of citizens I have proposed in the preceding sections? Though I cannot here offer a full and exhaustive accounting of these conditions, I would like to briefly sketch two candidate criteria in the form of questions that may guide thoughtful evaluation. Though these criteria suggest only the riskiness of teaching hope rather than a fuller rejection of the practice, I submit that they are useful in demonstrating how one might begin thinking and acting beyond a hope-centric model.

\section{CANDIDATE 1: ALETHIC CRITERION (I.E., REGARDING ONE'S RELATIONSHIP TO THE WORLD)}

When might teaching hope potentially risk moving us away from truth? This seems an especially important educational question. In the first and second of the three reasons I offered above, this might be the case. Specific groups within a society might be vulnerable such that an education that prioritizes hope might render them even more susceptible to being diverted from various

political or civic truths of their circumstances. Similarly, it might be appropriate for some groups to have an education that explicitly offers multiple motivators for civic engagement (in this, of course, hope might be included, but it would be de-centered in ways that avoid many of the concerns I have thus far explored). In this way (and potential others), an eye towards truth in assessment and available options for response might suggest that something other than hope hold curricular priority in democratic societies.

\section{CANDIDATE 2: HERMENEUTIC CRITERION (I.E., REGARDING ONE'S RELATIONSHIP TO ONE'S SELF)}

When might teaching hope risk distorting one's ability to perceive one's authentic experience? That is, could teaching hope to those who have little reason to embrace pragmatist hope, visit upon them some deleterious effect, rendering 
their own circumstances less clear to themselves (and others)? It seems to me that this could be possible under all three of the reasons against hope offered above. That is, a politically focused and civically engaged, yet non-hopeful person might be miseducated were she led towards a view of hope that causes her to doubt her own claims of sober political analysis, flattens her reading of her own active engagement, and alienates her from her (justified?) feelings of non-hopefulness. In this way (and potential others), an eye towards fidelity in one's interpretations, and/or the psychological benefit of accurate self-legibility, might suggest that something other than pragmatist hope ought to hold curricular priority. Of course, given the collective focus of the pragmatist hope project outlined by Stitzlein, it might be most useful to consider when these criteria (i.e., Alethic, Hermeneutic, or others more preferable to the task) truly apply in meaningful and patterned ways for groups of citizens attempting the difficult democratic work of the American experiment.

\section{CONCLUSION}

In closing, I must again note that Stitzlein's project offers much to western democracies in the grips of truly difficult political moments. A key strength of this engrossing and measured book is the way in which its focus on the American context allows it to offer fairly specifically informed recommendations linked to a complex argument regarding the role of values and dispositions in the service of together stretching towards our highest ideals. That Stitzlein is able to demonstrate the essential role of education in much of this is a real asset in expanding the reach of philosophy of education.

In my focusing, over the course of these pages, on the core idea of hope and its credible limitations, I have attempted to offer friendly provocation for future directions of this worthy project. An expanded view of hope might allow many of the insights of this excellent text to more clearly apply to those with fraught relationships with hope. Developed further than the boundaries of the book, Stitzlein's analyses can be understood to pose deeply intriguing questions of civic education. Not least of these might be engaged via the two questions implied in much of my above engagement with her project. Firstly, one might remain curious regarding how Stitzlein would respond to the claim 
that many of her recommendations could indeed operate without pragmatist hope as the motivator for their pursuit.

Secondly, how might Stitzlein regard my claimed possibility of meliorism amidst a degree of political melancholia? It strikes me that answers to these questions push at our sense of the stakes and borders of an education for sustained civic responsibility. I certainly remain bopeful that Stitzlein's future work will continue to explore this incredibly fertile terrain.

1 Thomas Carothers and Andrew O’Donohue, eds., Democracies Divided: The Global Challenge of Political Polarization (Washington: Brookings Institution Press, 2019); Steven Levitsky and Daniel Ziblatt, How Democracies Die (New York: Penguin Random House, 2018).

2 Sarah M. Stitzlein, Learning How to Hope: Reviving Democracy Through our Schools and Civil Society (Oxford: Oxford University Press, 2020), 2. 3 Stitzlein, Learning How to Hope, 12 \& 15.

4 Stitzlein, 3.

5 Stitzlein, 52-59. 